\title{
Epidemiologic and Clinicopathologic Features of Advanced Hepatocellular Carcinoma
}

\author{
Maha L. Zamzam \\ Department of Clinical Oncology and Nuclear Medicine, Faculty of Medicine, Suez Canal University, Ismailia, Egypt \\ Email: mahalzamzam@hotmail.com
}

How to cite this paper: Zamzam, M.L. (2019) Epidemiologic and Clinicopathologic Features of Advanced Hepatocellular Carcinoma. Journal of Cancer Therapy, 10, 411-421.

https://doi.org/10.4236/jct.2019.106034

Received: May 1, 2019

Accepted: June 1, 2019

Published: June 4, 2019

Copyright $\odot 2019$ by author(s) and Scientific Research Publishing Inc. This work is licensed under the Creative Commons Attribution International License (CC BY 4.0).

http://creativecommons.org/licenses/by/4.0/

\begin{abstract}
Background: Hepatocellular carcinoma (HCC) is one of the most common malignant tumors worldwide as well as in Egypt where it constitutes a significant public health problem. HCC is the third most common cause of death from cancer and chronic infection with HBV and HCV are the most important precursors for HCC development. Objective: To study the epidemiologic, clinical and pathological features of advanced HCC in clinical oncology and Nuclear medicine department, Suez Canal University hospital. Method: This is a retrospective study done to analyse the clinical, demographic and pathological data of advanced HCC patients that attended clinical oncology and Nuclear Medicine Department, Suez Canal University Hospital in the period between January 2013 and December 2016. Results: Results revealed that mean age of the patients was $60.2 \pm 7.69,71.74 \%$ male and $28.26 \%$ Female, 91.3\% were HCV positive while $6.5 \%$ were HBV positive. Liver cirrhosis was in $89.13 \%$ of patients. Majority of the patients $(78.2 \%)$ were child Pugh Score B and 21.7\% were child Pugh Score C. 67.39\% of patients had diabetes. Portal vein thrombosis was present in $50 \%$ of cases. Alpha fetoprotein was elevated $>400$ in $56.52 \%$ of cases. Thirty four patients received treatment in the form of chemotherapy while 12 patients did not receive treatment. There is a highly significant increase in survival time $\mathrm{P}<0.001$ in treated group compared to untreated group. Median survival time (in months) was five months in the treated group versus one month in the untreated group. Conclusion: HCC is one of the increasing major health problems in both developing and developed countries. The most important risk factor is cirrhosis which is mainly due to HCV infection. Thus, much effort should be put into the field of prevention and treatment of viral hepatitis infections and chronic liver disease. Screening programs should be done to get rid of the problem, and most importantly, there must be an acceptable and effective therapy for HCC.
\end{abstract}

\section{Keywords}

Hepatocellular Carcinoma, Epidemiologic, Clinicopathologic Survival 


\section{Introduction}

Hepatocellular carcinoma (HCC) is the most common form of primary liver cancer (Poustchi, 2010) [1]. Worldwide, liver cancer is the fifth and seventh most common cancer in men and women, respectively. Regions of high incidence include Eastern and South-Eastern Asia, Middle and Western Africa (Ferlay, et al., 2014) [2]. HCC is the third most common cause of death from cancer. HCC high fatality is reflected in high mortality (0.93) to incidence ratio (Ferlay, et al., 2014) [2].

In Egypt, liver cancer is the fourth most common cancer and is the second cause of cancer mortality in both sexes (Ferlay, et al., 2014) [2].

Risk factors of HCC are many and include viral hepatitis C (HCV) and B (HBV), cirrhosis, alcohol, aflatoxins, male sex and smoking (Ahmed and Rabinovitz, 2005) [3]. Chronic infection with HBV and HCV are the most important precursors for HCC development, together accounting for over $80 \%$ of liver cancer cases worldwide (Bosch, et al., 1999) [4].

In Egypt, HCV is the main risk factor for HCC where $71 \%$ of HCC cases are positive for anti-HCV antibodies (Rahman, et al., 2001) [5].

A considerable number of patients are diagnosed at advanced stage with poor prognosis and a median overall survival (OS) of about 6 months. Sorafenib is the only approved front-line molecular-targeted treatment with slight survival benefits. It improves survival with median OS rate of 6.5 - 10.7 months (Llovet, et al., 2008) [6].

Prognosis of advanced HCC is poor with median OS less than 6 months. This is even less in low and middle income countries, where resources and access to therapy are limited (Llovet, et al., 1999) [7].

The aim of this study was to analyze the epidemiologic and clinical characteristics of advanced HCC cases at Clinical Oncology and Nuclear Medicine Department, Suez Canal University in the period from January 2013 to December 2016.

\section{Patient and Methods}

This is a retrospective study in which all cases of advanced HCC attended clinical oncology and nuclear medicine department, Suez Canal University hospital in the period from January 2013 till end of December 2016 were enrolled in the study. Forty six cases of advanced HCC attended the department during this period and their medical records were reviewed for the following variables: age, sex, residence, special habits and treatment of other medical diseases. Diagnosis of HCC was based on clinical, imaging and histopathological findings. Diagnosis was achieved by ultrasonographic guided biopsy from the lesions, HCC radiological criteria in triphasic CT or presence of lesion by sonar and rising alpha feto protein. Clinical data as regards symptoms, signs and child Pugh classification were also reviewed. Associated risk factors HCV, HBV, and cirrhosis were recorded. Level of alpha fetoprotein and stage of primary tumor, regional lymph node involvement, presence and site of metastasis and type of treatment re- 
ceived, were also reviewed. Follow up of cases to evaluate survival and death.

Overall survival (OS) was defined as the time from diagnosis until death.

\section{Statistical Analysis}

Data were collected, revised, coded and entered to the Statistical Package for Social Science (IBM SPSS) version 23. The quantitative data were presented as mean, standard deviations and ranges when their distribution found parametric. Also qualitative variables were presented as number and percentages.

The confidence interval was set to $95 \%$ and the margin of error accepted was to $5 \%$. So, the p-value was considered significant at the level of $<0.05$.

The Kaplan-Meier method was used to produce survival curves.

\section{Results}

Forty six advanced hepatocellular carcinoma patients attended Clinical oncology and Nuclear Medicine Department, Suez Canal University Hospital in the period from January 2013 to December 2016.

Mean age of the patients was $60.2 \pm 7.69$. The majority of patients were males (71.74\%) Most of patients (76.09\%) were from Ismailia. 39.13\% were smokers (Table 1).

91.3\% were HCV positive while 6.5\% were HBV positive. Liver cirrhosis was in $89.13 \%$ of cases. Regarding child Pugh classification, $78.26 \%$ were Child B while $21.73 \%$ were Child C $67.39 \%$ of patients had diabetic and $71.74 \%$ were hypertensive (Table 2).

Abdominal pain was the first presenting symptom in $73.91 \%$ of cases (Table 3).

Majority of patients (47.83\%) presented with stage III a (Table 4). Most of patients were metastatic (54.35\%) while $45.65 \%$ did not have metastasis (Table 5).

Portal vein thrombosis was present in $50 \%$ of cases (Table 6). Alpha Fetoprotein

Table 1. Shows frequency distribution of the studied patients according to their socio demographic characteristics.

\begin{tabular}{cccc}
\hline & & \multicolumn{2}{c}{ Total $(\mathrm{N}=46)$} \\
\hline \multirow{2}{*}{ Age (years) } & Mean \pm SD & \multicolumn{2}{c}{$60.2 \pm 7.69$} \\
& Range & \multicolumn{2}{c}{$50-76$} \\
Sex & No. & $\%$ \\
\hline Mesidence & Female & 33 & 71.74 \\
& Ismailia & 13 & 28.26 \\
& Port-said & 35 & 76.09 \\
Suez & 1 & 2.17 \\
History of smoking & + & 10 & 21.74 \\
& $-a$ & 18 & 39.13 \\
\hline
\end{tabular}

Chi-square test "Fisher Exact Test": a-P $<0.05$. 
Table 2. Distribution of patients according to risk factors.

\begin{tabular}{cccc}
\hline & & \multicolumn{2}{c}{ Total $(\mathrm{N}=46)$} \\
\cline { 3 - 4 } HCV & & No. & $\%$ \\
\hline HBV & - & 42 & 91.3 \\
& + & 4 & 8.69 \\
Liver cirrhosis & $+^{\mathrm{a}}$ & 3 & 6.521 \\
& + & 43 & 93.47 \\
Child Pugh classification & - & 41 & 89.13 \\
& Child B & 5 & 10.8 \\
History of chronic diseases & Child C & 10 & 78.26 \\
& DM & 31 & 21.73 \\
& HTN & 33 & 67.39 \\
& Cardiac disease & 12 & 71.74 \\
& & & 26.09 \\
\hline
\end{tabular}

Fisher Exact Test: a-P $<0.05$.

Table 3. Distribution of patients according to the first presenting symptom.

\begin{tabular}{ccc}
\hline \multirow{2}{*}{ Symptom } & \multicolumn{2}{c}{ Total $(\mathrm{N}=46)$} \\
\cline { 2 - 3 } & Frequency & $\%$ \\
\hline Accidentally discovered & 8 & 17.39 \\
Abdominal pain & 34 & 73.91 \\
Weight loss & 5 & 10.87 \\
Anorexia & 9 & 19.57 \\
Dyspnea & 4 & 8.69 \\
Abdominal mass & 7 & 15.22 \\
Bleeding & 4 & 8.69 \\
\hline
\end{tabular}

Table 4. Distribution of patients according to stages of HCC (Stage TNM Staging (Edge, et al., 2010)).

\begin{tabular}{ccc}
\hline & \multicolumn{2}{c}{ Total $(\mathrm{N}=46)$} \\
\cline { 2 - 3 } & No. & $\%$ \\
\hline Stage III a & 22 & 47.83 \\
Stage III b & 3 & 6.52 \\
Stage III c & 10 & 21.74 \\
Stage IV & 11 & 23.91 \\
\hline
\end{tabular}

Chi-square test: $\mathrm{a}-\mathrm{P}<0.001$.

was elevated $>400$ in $56.52 \%$ of cases (Table 7). Hepatic encephalopathy was the commonest cause of death which was in $43.48 \%$ of patients (Table 8 ).

Thirty four $(73.91 \%)$ patients received treatment while 12 (20.09\%) patients did 
not receive treatment (Table 9). Overall survival was significantly related to treatment. There is a highly significant increase $(\mathrm{P}<0.001)$ in survival time (in months) in treated group $(6.036 \pm 3.75)$ compared to untreated group (1.636 \pm 1.21). Median survival time (in months) was five months in the treated group versus one month in the untreated group. No one in the untreated group reached 6 months or one year survival, while in treated group only $12.0 \%$ reached one year and $44.0 \%$ reach 6 months survival rate (Table 10 and Figure 1).

Table 5. Distribution of patients according to the site of metastasis.

\begin{tabular}{ccc}
\hline & \multicolumn{3}{c}{ Total $(\mathrm{N}=46)$} \\
\cline { 2 - 3 } & No. & $\%$ \\
\hline None & 21 & 45.65 \\
Bone & 6 & 13.04 \\
Lung & 5 & 10.87 \\
Abdominal L.N & 14 & 30.44 \\
\hline
\end{tabular}

Chi-square test: $\mathrm{P}<0.001$.

Table 6. Distribution of participants according to presence of portal vein thrombosis.

\begin{tabular}{cccc}
\hline & \multicolumn{2}{c}{ Total $(\mathrm{N}=46)$} \\
\cline { 3 - 3 } & & No. & $\%$ \\
\hline Portal vein thrombosis & + & 23 & 50.0 \\
& - & 23 & 50.0 \\
\hline
\end{tabular}

Chi-square test: No significant difference.

Table 7. Distribution of participants according to level of alpha-fetoprotein \& biopsy.

\begin{tabular}{cccc}
\hline & & \multicolumn{2}{c}{ Total $(\mathrm{N}=46)$} \\
\cline { 3 - 4 } & & No. & $\%$ \\
\hline \multirow{3}{*}{ Level of alpha-fetoprotein $^{\mathrm{a}}$} & Elevated $>400$ & 6 & 13.04 \\
& Elevated $<400$ & 26 & 56.52 \\
Biopsy & + & 14 & 30.44 \\
& - & 31 & 32.61 \\
\hline
\end{tabular}

Chi-square test: $\mathrm{a}-\mathrm{P}<0.001$.

Table 8. Distribution of patients according to cause of death.

\begin{tabular}{ccc}
\hline & \multicolumn{2}{c}{ Total $(\mathrm{N}=46)$} \\
\cline { 2 - 3 } & No. & \% \\
\hline Hematemesis & 6 & 13.04 \\
Lower G.I.T bleeding & 7 & 15.22 \\
Hepatic encephalopathy & 20 & 43.48 \\
Unknown & 13 & 28.26 \\
\hline
\end{tabular}

Chi-square test: $\mathrm{P}<0.001$. 
Table 9. Distribution of participants according to the treatment status.

\begin{tabular}{ccc}
\hline & \multicolumn{2}{c}{ Total $(\mathrm{N}=46)$} \\
\cline { 2 - 3 } & No. & $\%$ \\
\hline Treated & 34 & 73.91 \\
Untreated & 12 & 26.09 \\
\hline
\end{tabular}

Table 10. Showing means and medians for survival time (death).

\begin{tabular}{ccccc}
\hline & $\begin{array}{c}\text { Median Survival Time } \\
\text { (In months) }\end{array}$ & $\begin{array}{c}\text { Survival Time (In } \\
\text { months) Mean } \pm \text { SD }\end{array}$ & $\begin{array}{c}\text { One-year } \\
\text { Survival Rate }\end{array}$ & $\begin{array}{c}\text { 6-month } \\
\text { Survival Rate }\end{array}$ \\
\hline Treated $(\mathrm{N}=34)$ & 5.5 & $6.036 \pm 3.75^{\mathrm{a}}$ & $12.0 \%$ & $44.0 \%$ \\
Untreated $(\mathrm{N}=12)$ & 1.0 & $1.636 \pm 1.21$ & $0.0 \%$ & $0.0 \%$ \\
Total $(\mathrm{N}=46)$ & 4.56 & $3.0 \pm 3.7$ & $8.7 \%$ & $32.6 \%$ \\
\hline
\end{tabular}

Student t-test: a-P $<0.001$.

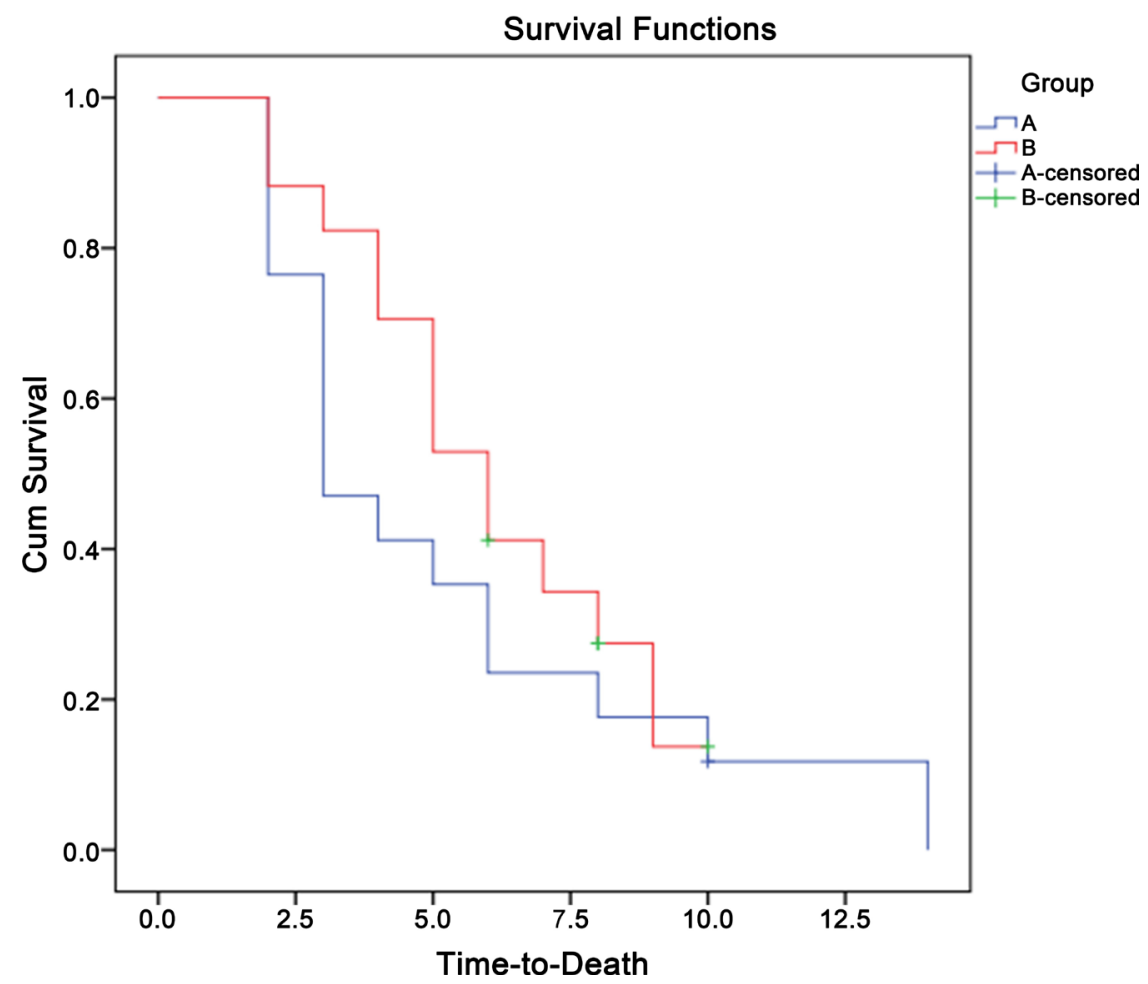

Figure 1. Showing comparison of survival function between both groups.

Table 11 and Figure 2 shows that the mean of survival time and one-year survival rate were approximated in both patients with negative and positive portal venous thrombosis. The 6 months survival rate was higher (39.13\%) in patients with positive portal venous thrombosis, than those with negative (26.09) portal venous thrombosis.

Survival was compared according to whether patients received treatment or no specific treatment was received. Thirty four patients received chemotherapy treatment in the form of Gemcitabine and Oxaliplatin or oral capecitabine or 
Table 11. Showing Medians, One-year Survival Rate \& 6-month Survival Rate and Survival Time (in relation to Portal Venous Thrombosis).

\begin{tabular}{ccccc}
\hline & PVT & $\begin{array}{c}\text { Survival Time (In } \\
\text { months) Mean } \pm \text { SD }\end{array}$ & $\begin{array}{c}\text { One-year Survival } \\
\text { Rate }\end{array}$ & $\begin{array}{c}\text { 6-month Survival } \\
\text { Rate }\end{array}$ \\
\hline \multirow{2}{*}{ Total $(\mathrm{N}=46)$} & -ve & $4.59 \pm 3.9$ & $8.7 \%$ & $26.09 \%$ \\
& +ve & $4.52 \pm 3.59$ & $8.7 \%$ & $39.13 \%$ \\
\hline
\end{tabular}

Student t-test: $\mathrm{a}-\mathrm{P}<0.01 \mathrm{~b}-\mathrm{P}<0.001$.

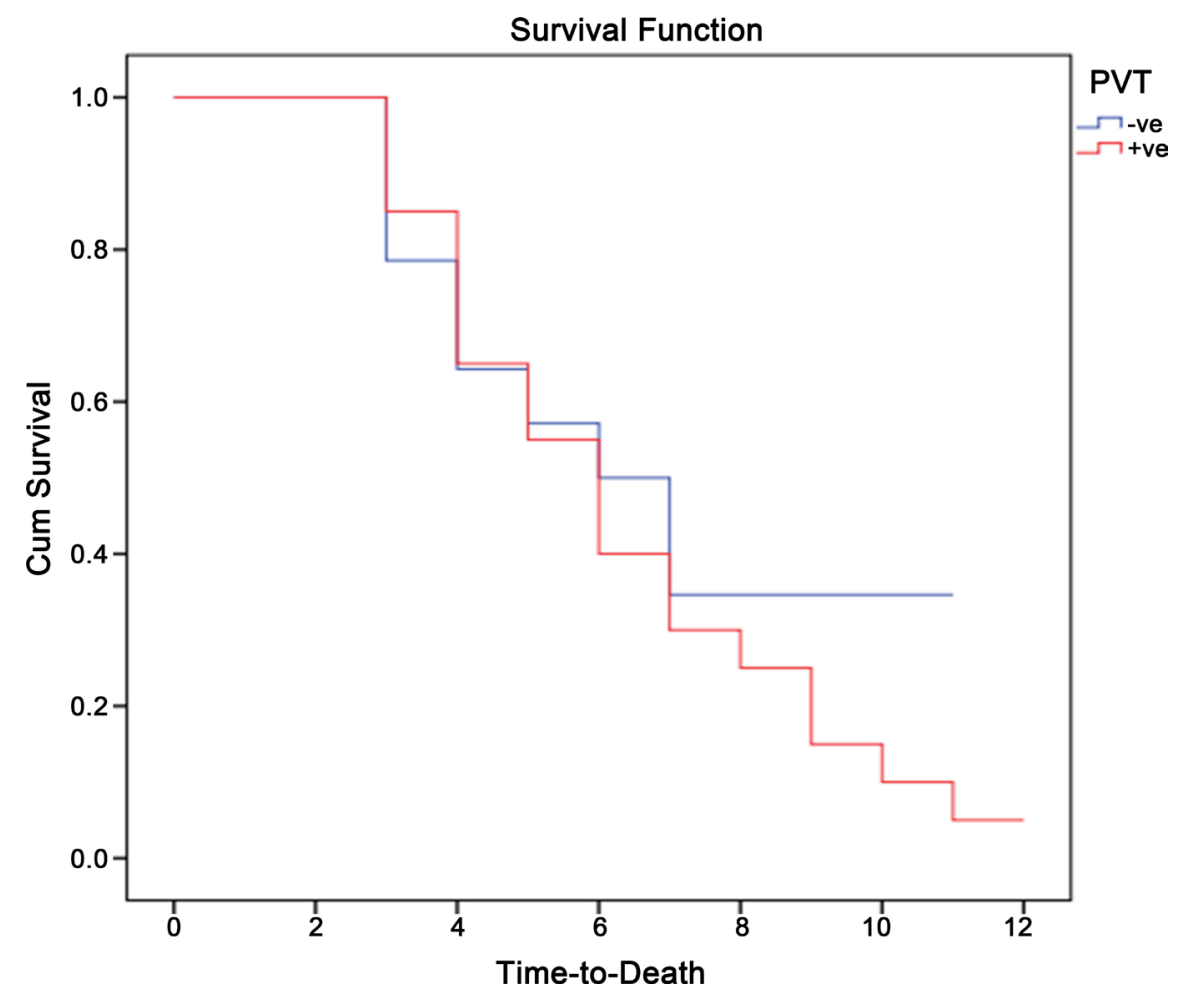

Figure 2. Overall one-year Survival Curves in patients with/without PVT.

adriamycin or low dose prolonged infusion Gemcitabine. Twelve patients didn't receive treatment. Main causes for non-treatment were the presence of comorbidities, poor liver function, refusal of treatment, and limited access to systemic treatment due to unavailability and absence of national insurance system to cover all patients in Egypt.

\section{Discussion}

Hepatocellular carcinoma is a major health problem in Egypt and many patients present with advanced disease beyond curative surgery and effective local and regional therapies. Treatment of HCC remains palliative with a minimal survival benefit. In this study, we analysed epidemiology, clinical features and survival in 46 advanced HCC who attended clinical oncology and Nuclear Medicine Department, Suez Canal University.

The advantage of the current study is that it included patients received treatment and patients that did not receive treatment due to refusal, unavailability or 
being unfit for therapy.

The age of our patients ranged from 50 - 76 years old. Most of our patients were males (71.74\%) and only $28.26 \%$ were females. This result is in agreement with Shripad B. Pande, et al. 2012 [8] who found in his study on HCC that majority of patients $79 \%$ were males and $21 \%$ were females. This may be in part explained by differences in exposure to risk factors. Also, Kuman R et al. 2008 [9] in India, mentioned that the incidence of HCC in males is higher than females.

As regards hepatitis, $91.3 \%$ of our patients were $\mathrm{HCV}+\mathrm{ve}$, while $6.5 \%$ were $\mathrm{HBV}+\mathrm{ve}$. This is in agreement with other studies as Gomaa et al., 2008 [10] who mentioned that HCV is the most important risk factor for HCC in Western European and North American countries where $70 \%$ of patients with HCC have anti-HCV antibody in the serum.

Previously, there was strong evidence that hepatitis B virus (HBV) was the major cause of HCC in Egypt. Recently, HCV has become the predominant factor associated with the more recent epidemic of HCC. Egypt has been documented to have one of the highest prevalence rates of HCV infection in the world (Anwar WA et al., 2008) [11] and this is totally agreed with our results.

Liver cirrhosis was present in $89.13 \%$ of cases in our study. This is in agreement with Fattovich [12] G et al., 2004 who stated that cirrhosis underlies HCC in approximately $80 \%-90 \%$ of cases. This is in agreement also with a study done by Abdelaziz [13] AO et al., 2014 in a specialized multidisciplinary clinic for HCC in Kasr El Eini Hospital, Cairo University, Egypt where he found that all cases developed HCC on top of cirrhosis which was mainly due to HCV (71\%).

Our results showed that the most common extrahepatic metastases of hepatocellular carcinoma were abdominal lymph nodes $30.4 \%$ followed by bone $13.04 \%$ a and lung $10.87 \%$. This is in agreement with the studies done by Natsuizaka MI et al., 2005 [14] who found that the lung, abdominal lymph nodes and bone are the most common sites of extrahepatic metastatic HCC but with different arrangement as they mentioned that the most common site was the lung, abdominal lymph nodes and bone.

As regards portal vein thrombosis, it was present in $50 \%$ of cases. This is in contrast to Matthew Quirk et al., 2015 [15] and Minagawa M et al., 2006 [16] who reported lower percentage of portal vein thrombosis (10-40\%) of HCC at the time of diagnosis.

Diabetes is associated with a $2-3$ fold increase in the risk of HCC, regardless of the presence of other major HCC risk factors (Davita, et al., 2005) [17]. This was in accordance with the significantly higher risk of DM in HCC patients (Ziada et al., 2016 [18]).

Smoking increases the risk of HCC in patients with viral hepatitis. Cigarettes are a major source of 4 aminobiphenyls; a hepatic carcinogen which has been implicated as a casual risk factor for HCC [19] [20]. Also, Baghdady et al. mentioned that smoking increased the risk of HCC development independent of HCV and HBV infections in Egyptian cirrhotic patients [21]. In spite of this, 
history of smoking in this study was positive in $39.1 \%$ of cases and negative in $60.8 \%$ of cases. This may be due to the small number of patients in our study.

In the present study, the median survival time in the treated group was 5.5 months versus 1 month in the untreated group, highly statistical significant $\mathrm{P}<$ 0.001. However, the results of overall survival of untreated HCC in several series were comparable to our results. Zeeneldin AA, et al. who performed a study at Tanta Cancer Center, Egypt reported that the median overall survival of untreated HCC was 2.3 months [22] [23]. Also, Pawarode A, et al. and Yeung YP, et al. reported median overall survival of 2 - 3 months in untreated hepatocellular carcinoma [24] [25]. Also, Natalia, et al. reported in their study that the median overall survival of untreated hepatocellular carcinoma was 3.6 months [26].

\section{Conclusions}

HCC is one of the increasing major health problems in both developing and developed countries. HCC (>80\%) majorly presents with advanced or unresectable diseases. Most HCC patients have underlying cirrhosis with impaired hepatic function.

Owing to the aggressive biology of the disease and the limited treatment options for HCC patients as well as the limited resources or access to treatment for most of Egyptian patients like sorafenib or liver transplant, we found that HCC is a fatal disease and constitutes a major national problem. Thus, we have to find other effective treatment modalities or try to stress the importance of screening programs which can enable diagnosis at an early stage with the opportunity for treatment with curative intent. The most valuable solution is to put more effort into a prevention program, through prevention of infection by viral hepatitis or treating it at earlier stages before causing cirrhosis which is the main risk factor for HCC in Egypt.

Therefore, improving screening, early detection and access to therapy may improve outcome of HCC.

\section{Conflicts of Interest}

The authors declare no conflicts of interest regarding the publication of this paper.

\section{References}

[1] Poustchi, H., Sepanlou, S., Esmaili, S., Mehrabi, N. and Ansarymoghadam, A. (2010) Hepatocellular Carcinoma in the World and the Middle East. Middle East Journal of Digestive Diseases, 2, 31-41.

[2] Ferlay, J., Shin, H.R., Bray, F., et al. (2010) Cancer Incidence and Mortality Worldwide: IARC Cancer Base No. 10. IARC Press, Lyon, France. http://globocan.iarc.fr.

[3] Ahmad, J. and Rabinovitz, M. (2005) Etiology and Epidemiology of Hepatocellular Carcinoma. In: Carr, B.I., Ed., Current Clinical Oncology, Humana Press Inc., Totowa, 1-22. https://doi.org/10.1007/978-1-59259-844-1_1

[4] Bosch, F.X., Ribes, J. and Borras, J. (1999) Epidemiology of Primary Liver Cancer. 
Seminars in Liver Disease, 19, 271-285. https://doi.org/10.1055/s-2007-1007117

[5] El-Zayadi, A.R., Abaza, H., Shwaky, S., et al. (2001) Prevalence and Epidemiological Features of Hepatocellular Carcinoma in Egypt-A Single Centre Experience. $\mathrm{He}$ patology Research, 19, 170-179. https://doi.org/10.1016/S1386-6346(00)00105-4

[6] Llovet, J.M., Ricci, S., Mazzaferro, V., et al. (2008) Sorafenib in Advanced Hepatocellular Carcinoma. The New England Journal of Medicine, 359, 378-390.

https://doi.org/10.1056/NEJMoa0708857

[7] Llovet, J.M., Bustamante, J., Castells, A., et al. (1999) Natural History of Untreated Nonsurgical Hepatocellular Carcinoma: Rationale for the Design and Evaluation of Therapeutic Trials. Hepatology, 29, 62-67. https://doi.org/10.1002/hep.510290145

[8] Pande, S.B., Doval, D.C., Pavithran, K., et al. (2012) Gemcitabine and Cisplatin-Based Combination Chemotherapy in Advanced Hepatocellular Carcinoma: An Indian Experience. Indian Journal of Medical and Paediatric Oncology, 33, 42-47. https://doi.org/10.4103/0971-5851.96968

[9] Kumar, R., Saraswat, M.K., Sharma, B.C., et al. (2008) Characteristics of Hepatocellular Carcinoma in India. A Retrospective Analysis of 191 Cases. QJM: An International Journal of Medicine, 101, 479-485. https://doi.org/10.1093/qjmed/hcn033

[10] Gomaa, A.I., Khan, S.A., Toledano, M.B., et al. (2008) Hepatocellular Carcinoma Epidemiology, Risk Factors and Pathogenesis. World Journal of Gastroenterology, 14, 4300-4308. https://doi.org/10.3748/wjg.14.4300

[11] Anwar, W.A., Khaled, H.M., Amra, H.A., et al. (2008) Changing Pattern of Hepatocellular Carcinoma (HCC) and Its Risk Factors in Egypt: Possibilities for Prevention. Mutation Research/Reviews in Mutation Research, 659, 176-84. https://doi.org/10.1016/j.mrrev.2008.01.005

[12] Fattovich, G., Stroffolini, T., Zagni, I., et al. (2004) Hepatocellular Carcinoma in Cinhosis: Incidence and Risk Factors. Gastroenterology, 127, S35-S50.

https://doi.org/10.1053/j.gastro.2004.09.014

[13] Abdelaziz, A.O., Elbaz, T.M., Shousha, H.I., et al. (2014) Survival and Prognostic Factors for Hepatocellular Carcinoma an Egyptian Multidisciplinary Clinic Experience. Asian Pacific Journal of Cancer Prevention, 15, 3915-3920. https://doi.org/10.7314/APJCP.2014.15.9.3915

[14] Natsuizaka, M.I., Omura, I., Akaike, T., et al. (2005) Clinical Features of Hepatocellular Carcinoma with Extrahepatic Metastases. Journal of Gastroenterology and Hepatology, 20, 1781-1787. https://doi.org/10.1111/j.1440-1746.2005.03919.x

[15] Quirk, M., Kim, Y.H., Saab, S., et al. (2015) Management of Hepatocellular Carcinoma with Portal Vein Thrombosis. World Journal of Gastroenterology, 21, 3462-3471. https://doi.org/10.3748/wjg.v21.i12.3462

[16] Minagawa, M., Makuuchi, M., et al. (2006) Treatment of Hepatocellular Carcinoma Accompanied by Portal Vein Tumor Thrombus. World Journal of Gastroenterology, 12, 7561-7567. https://doi.org/10.3748/wjg.v12.i47.7561

[17] Davita, J.A., Morgan, R.O., Shaib, Y., McGlynn, K.A. and El-Serag, H.B. (2005) Diabetes Increases the Risk of Hepatocellular Carcinoma in the United States: A Population Based Case Control Study. Gut, 54, 533-539.

https://doi.org/10.1136/gut.2004.052167

[18] Ziada, D.H., El Sadany, S., Soliman, H., et al. (2016) Prevalence of Hepatocellular Carcinoma in Chronic Hepatitis C Patients in Mid Delta, Egypt: A Single Center Study. Journal of the Egyptian National Cancer Institute, 28, 257-262.

https://doi.org/10.1016/j.jnci.2016.06.001 
[19] El-Zyadi, A.R. (2006) Heavy Smoking and Liver. World Journal of Gastroenterology, 12, 6098-6101. https://doi.org/10.3748/wjg.v12.i38.6098

[20] Koh, W.P., Robien, K., Wang, R., Govindarajan, S., Yuan, J.M. and Yu, M.C. (2011) Smoking as an Independent Risk Factor for Hepatocellular Carcinoma: The Singapore Chinese Health Study. British Journal of Cancer, 105, 1430-1435. https://doi.org/10.1038/bjc.2011.360

[21] Baghdady, I., El-Kaffrawy, N., El-Atti, E.A., et al. (2013) Study of the Risk Factors for Hepatocellular Carcinoma: Effect of Their Synergism. Journal of American science, 9, 211-217.

[22] Zeeneldin, A.A., Salem, S.E., Darwish, A.D., et al. (2015) Untreated Hepatocellular Carcinoma in Egypt: Outcome and Prognostic Factors. Journal of Hepatocellular Carcinoma, 2015, 3-9. https://doi.org/10.2147/JHC.S73828

[23] Mohmad, N.H., El Zawahry, H.M., Mokbtar, N.M., et al. (2000) Review of Epidemiologic and Clinicopathologic Features of 403 Hepatocellular Carcinoma (HCC) $\mathrm{Pa}$ tients. Journal of the Egyptian National Cancer Institute, 12, 87-93.

[24] Pawarde, A., Voravud, N., Sriuranpong, V., et al. (1998) Natural History of Untreated Primary Hepatocellular Carcinoma: A Retrospective Study of 157 Patients. American Journal of Clinical Oncology, 21, 386-391. https://doi.org/10.1097/00000421-199808000-00014

[25] Yeung, Y.P., Lo, C.M., Liu, C.L., et al. (2005) Natural History of Untreated Nonsurgical Hepatocellular Carcinoma. American Journal of Gastroenterology, 100, 1995-2004.

[26] Khalaf, N., Ying, J., Mittal, S., et al. (2017) Natural History of Untreated Hepatocellular Carcinoma in a US Cohort and the Role of Cancer Survillance. Clinical Gastroenterology and Hepatology, 15, 273-281.

https://doi.org/10.1016/j.cgh.2016.07.033 